\title{
Trudne wybory u pacjentów z wysokim ryzykiem powikłań zakrzepowo-zatorowych i krwotocznych - przypadek 81-letniej pacjentki z wysokim ryzykiem udaru mózgu po przebytym epizodzie krwawienia z przewodu pokarmowego
}

\section{Challenging choices in patients with both high thromboembolic and bleeding risk - clinical case of 81-year-old woman with high risk of stroke after gastrointestinal bleeding event}

\author{
Maciej Krzysztof Kluk ${ }^{1}$, Kamilla Wesołowska ${ }^{1}$, \\ Agnieszka Woronowicz-Chróściel ${ }^{1}$, Beata Wożakowska-Kapłon ${ }^{1,2}$ \\ ${ }^{1}$ I Klinika Kardiologii i Elektroterapii Świętokrzyskiego Centrum Kardiologii w Kielcach \\ ${ }^{2}$ Wydział Lekarski i Nauk o Zdrowiu Uniwersytetu Jana Kochanowskiego w Kielcach
}

\section{Streszczenie}

Problem poważnych powikłań krwotocznych, takich jak krwawienie z przewodu pokarmowego, stanowi główne ryzyko związane z przewlekłym leczeniem przeciwkrzepliwym, w tym za pomocą doustnych antykoagulantów niebędących antagonistami witaminy K (NOAC), u pacjentów z migotaniem przedsionków. Prezentowany przypadek 81-letniej chorej ukazuje, że przebycie zagrażającego życiu epizodu krwawienia z przewodu pokarmowego nie jest przeciwwskazaniem do ponownego włączenia NOAC, szczególnie w przypadku wysokiego ryzyka powikłań zakrzepowo-zatorowych. Dostępne NOAC pozwalają na dobór optymalnego leczenia dla chorego z uwzględnieniem wieku, funkcji nerek oraz punktacji w skalach $\mathrm{CHA}_{2} \mathrm{DS}_{2}$ VASc i HAS-BLED. Lekiem preferowanym u pacjentów obciążonych wysokim ryzykiem nawrotu krwawienia z przewodu pokarmowego i istotnie upośledzoną funkcją nerek jest apiksaban.

Słowa kluczowe: doustne antykoagualanty niebędące antagonistami witaminy K, ryzyko powikłań zakrzepowo-zatorowych, ryzyko krwawienia, krwawienie z przewodu pokarmowego, dabigatran, apiksaban

Folia Cardiologica 2016; 11, 3: 228-232

\section{Wstęp}

Jednym z głównych problemów klinicznych dotyczących terapii pacjentów z migotaniem przedsionków (AF, atrial fibrillation) jest dążenie do uzyskania równowagi między skutecznością profilaktyki powikłań zakrzepowo-zatorowych a ryzykiem wystąpienia istotnych klinicznie krwawień pod- czas leczenia przeciwkrzepliwego. Istotnym czynnikiem wpływającym na skuteczność i bezpieczeństwo przewlekłej antykoagulacji jest prawidłowy dobór rodzaju i dawki leku przeciwkrzepliwego, co wykazali Ruff i wsp. [1] w metaanalizie 4 badań randomizowanych z zastosowaniem doustnych antykoagulantów niebędących antagonistami witaminy $\mathrm{K}$ (NOAC, non-vitamin K oral anticoagulants). W porównaniu

Adres do korespondencji: lek. Maciej Krzysztof Kluk, I Klinika Kardiologii i Elektroterapii, Świętokrzyskie Centrum Kardiologii, ul. Grunwaldzka 45, 25-736 Kielce, faks: 413671 396, e-mail: maciej.kluk@gmail.com 
z warfaryną leki te, stosowane w pełnych dawkach dobowych (dabigatran $2 \times 150 \mathrm{mg}$, riwaroksaban $1 \times 20 \mathrm{mg}$, apiksaban $2 \times 5 \mathrm{mg}$ oraz edoksaban $1 \times 60 \mathrm{mg}$ ), skutecznie chronią przed udarem mózgu i zatorowością obwodową, ale jednocześnie istotnie zwiększają ryzyko krwawienia z przewodu pokarmowego, co może się wiązać z aktywnym działaniem leku w świetle przewodu pokarmowego. Zmniejszone dawki NOAC (dabigatran $2 \times 110 \mathrm{mg}$, edoksaban $1 \times$ $\times 30 \mathrm{mg}$ ) pozwalają zaś na porównywalną z zastosowaniem warfaryny ochronę przed powikłaniami zakrzepowo-zatorowymi, przy istotnie obniżonym ryzyku poważnych krwawień, w tym z przewodu pokarmowego [1]. Ryzyko powikłań krwotocznych zwiększa się wraz z wielkością dawki NOAC, jak pokazano na przykładzie dabigatranu w subanalizie badania RE-LY (Dabigatran versus Warfarin in Patients with Atrial Fibrillation); stosowanie dabigatranu w dawce 2 razy $150 \mathrm{mg} /$ dobę w porównaniu ze zmniejszoną dawką ( $2 \times 75 \mathrm{mg}$ ) oraz warfaryną wiązało się z istotnie wyższym ryzykiem wystąpienia poważnego krwawienia z przewodu pokarmowego (współczynnik ryzyka [HR, hazard ratio] 1,28; 95-proc. przedział ufności [Cl, confidence interval] 1,41-1,44) przy obniżonym ryzyku wystąpienia pozostałych punktów końcowych, w tym udaru niedokrwiennego mózgu (HR 0,80; 95\% Cl 0,67-0,96) [2]. Krwawienia z przewodu pokarmowego, w tym o klinicznie ciężkim przebiegu, wraz z krwawieniami wewnątrzczaszkowymi, to najczęstsze w praktyce klinicznej poważne epizody krwotoczne u pacjentów przewlekle leczonych przeciwkrzepliwie.

\section{Opis przypadku}

Kobiete w wieku 81 lat, w dobrym stanie biologicznym, od 2 lat - pod kontrola poradni rodzinnej - leczono dabigatranem w dawce 2 razy $150 \mathrm{mg}$ z powodu napadowego AF (wywiad arytmii od 4 lat, wcześniej leczenie warfaryną przy niestabilnych wartościach międzynarodowego współczynnika znormalizowanego [INR, international normalized ratio]). U chorej współwystępowały: pozawałowa dysfunkcja lewej komory - dotychczas bezobjawowa (frakcja wyrzutowa lewej komory 38\%, wywiad przebytego zawału ściany dolnej mięśnia sercowego 12 lat temu, przewlekłe zamknięcie prawej tętnicy wieńcowej oraz rozsiane nieistotne hemodynamicznie zwężenia w koronarografii wykonanej 5 lat temu z powodu niestabilnej dławicy piersiowej), nadciśnienie tętnicze, łagodne upośledzenie funkcji nerek (stężenie kreatyniny 1,4 mg/dl ze wskaźnikiem filtracji kłębuszkowej [GFR, glomerular filtration rate] 44,5 ml/min - ostatnie znane oznaczenie 4 lata temu), choroba refluksowa przełyku oraz choroba zwyrodnieniowa stawów kończyn dolnych. Pacjentkę leczono równolegle inhibitorem konwertazy angiotensyny (ramipril $2 \times 10 \mathrm{mg} / \mathrm{d}$.), indapamidem SR $(1 \times 1,5 \mathrm{mg})$, bisoprololem $(1 \times 2,5 \mathrm{mg})$, amiodaronem $(1 \times 200 \mathrm{mg})$, eplerenonem $(1 \times 25 \mathrm{mg})$ oraz statyną (atorwastatyna w dawce $1 \times 20 \mathrm{mg}$ ). W ostatnich 3 tygo- dniach pacjentka odczuwała nasilenie dolegliwości o charakterze refluksowym (okresowo stosowała z tego powodu ranitydynę), a także bóle prawego stawu biodrowego, z powodu których stosowała zwiększone dawki naproksenu (500 mg 2-3 ×/d.) (wywiad zebrany przy przyjęciu od rodziny i na podstawie dostępnej dokumentacji medycznej).

Pacjentka została przyjęta do kliniki chirurgii ogólnej w ciężkim stanie ogólnym z powodu objawów krwawienia z górnego odcinka przewodu pokarmowego (smoliste stolce od 2 dni, a w dniu przyjęcia epizod fusowatych wymiotów ze stanem przedomdleniowym), z anemizacją, cechami wstrząsu krwotocznego i zaostrzenia niewydolności nerek (tab. 1). W badaniu przedmiotowym zwracały uwagę objawy centralizacji krążenia, z miernie napiętym i niemiarowym tętnem na tętnicach udowych; w badaniach laboratoryjnych stwierdzono wydłużenie czasu częściowej tromboplastyny po aktywacji (aPTT, activated partial thromboplastin time), natomiast $\mathrm{w}$ badaniu elektrokardiograficznym - AF z przyspieszoną czynnością komór (tab. 1). Pacjentka głęboko podsypiała. Z wywiadu zebranego od rodziny wynikało, że ostatnią dawkę leku przeciwkrzepliwego przyjęła około 14 godzin przed przyjęciem do kliniki.

Chorą leczono w warunkach intensywnego nadzoru chirurgicznego (we współpracy z konsultującym kardiologiem) - zarówno przyczynowo (leczenie endoskopowe), jak i objawowo. W pilnie wykonanej panendoskopii stwierdzono aktywnie krwawiącą nadżerkę błony śluzowej antrum, którą ostrzyknięto adrenaliną z dobrym efektem hemostatycznym. Zastosowano parenteralnie inhibitor pompy protonowej oraz leki przeciwkrwotoczne (etamsylat, kwas traneksamowy). Przetoczono łącznie 3j. koncentratu krwinek czerwonych i 2 j. świeżo mrożonego osocza oraz prowadzono resuscytację płynową pod kontrolą bilansu płynów (z przejściowym epizodem obrzęku płuc opanowanym farmakoterapią). Odstawiono dabigatran, przy czym w okresie minimalnego stężenia leku we krwi utrzymywało się istotne wydłużenie aPTT, związane między innymi z upośledzoną funkcją nerek skutkującą kumulacją leku w osoczu. W leczeniu arytmii zastosowano strategię kontroli częstości rytmu (ze względu na cechy niewydolności nerek nie stosowano digoksyny, odstawiono również stosowany doustnie amiodaron). Zważywszy na hipotensję i cechy upośledzonego przesączania kłębuszkowego odstawiono inhibitor konwertazy angiotensyny. Dzięki wdrożonemu intensywnemu leczeniu uzyskano stopniową poprawę stanu ogólnego z powrotem świadomości, normalizację parametrów hemodynamicznych oraz poprawę parametrów morfotycznych i nerkowych (tab. 2). Po wyrównaniu niedokrwistości stwierdzono samoistny powrót rytmu zatokowego. W kontrolnej gastroskopii uwidoczniono nadżerki błony śluzowej żołądka w fazie gojenia (w okolicy antrum i wpustu) oraz infekcję Helicobacter pylori.

Zalecenia poszpitalne dla pacjentki obejmowały: modyfikację stylu życia (zalecenia dietetyczne), regularne 
Tabela 1. Wyniki badań dodatkowych przy przyjęciu do szpitala

\begin{tabular}{|c|c|}
\hline Oznaczenie/badanie & Wartość/opis \\
\hline \multicolumn{2}{|l|}{ Badania laboratoryjne } \\
\hline $\mathrm{RBC}[\mathrm{M} / \mu \mathrm{l}]$ & 2,90 \\
\hline Stężenie HGB [g/dl] & 7,3 \\
\hline Odsetek HCT (\%) & 24,4 \\
\hline 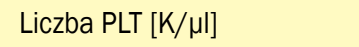 & 190 \\
\hline WBC $[\mathrm{K} / \mu \mathrm{l}]$ & 10,0 \\
\hline Stężenie hsTnT [ng/l] & 42 \\
\hline Glikemia przygodna [mg/dl] & 140 \\
\hline Stężenie kreatyniny [mg/dl] & 2,5 \\
\hline Stężenie mocznika [mg/dl] & 75 \\
\hline $\mathrm{CCr}[\mathrm{ml} / \mathrm{min}]$ & 30,3 \\
\hline Stężenie sodu [mEq/l] & 135 \\
\hline Stężenie potasu [mEq/l] & 5,0 \\
\hline INR & 1,0 \\
\hline aPTT [s] & 70 \\
\hline Stężenie ALT [j./I] & 90 \\
\hline Stężenie AST [j./I] & 75 \\
\hline Stężenie bilirubiny [mg/dl] & 1,5 \\
\hline Stężenie TSH [mjm./l] & 0,756 \\
\hline \multicolumn{2}{|l|}{ Inne parametry } \\
\hline Grupa krwi & $\mathrm{AB} \operatorname{RhD}(+)$ \\
\hline Wzrost [cm] & 168 \\
\hline Masa ciała [kg] & 87 \\
\hline $\mathrm{BMI}\left[\mathrm{kg} / \mathrm{m}^{2}\right]$ & 30,82 \\
\hline Ciśnienie tętnicze [mm Hg] & $70 / 40$ \\
\hline Rytm serca & $120 / \min$ \\
\hline Badanie EKG & AF ok. $120 / \mathrm{min}$ \\
\hline \multicolumn{2}{|c|}{$\begin{array}{l}\text { RBC (red blood count) - liczba krwinek czerwonych; HGB - hemoglobina; HCT (hematocrit) - he- } \\
\text { natokryt; PLT (platelets) - phytki; WBC (white blood count) - liczba krwinek białych; hsTNT (high- } \\
\text { sensitivity troponin T) - wysokoczuta troponina T; GFR (glomerular filtration rate) - wskaźnik fil- } \\
\text { racji kłebuszkowej; CCr (creatinine clearence) - klirens kreatyniny; INR (international normalized } \\
\text { atio) - mieddzynarodowy wspótczynnik znormalizowany; aPTT (activated partial thromboplastin } \\
\text { ime) - czas czésciowej tromboplastyny po aktywacji; AST (aspartate aminotransferase) - amino } \\
\text { rensferaza asparaginianowa; ALT (alanine aminotransferase) - aminotransferaza alaninowa; } \\
\text { SH (thyroid-stimulating hormone) - hormon tarczzycy; BMI (body mass index) - wskaźnik masy } \\
\text { iała; EKG - elektrokardiograficzne; AF (atrial fibrillation) - migotanie przedsionków }\end{array}$} \\
\hline
\end{tabular}

ambulatoryjne kontrole gastroenterologiczne i kardiologiczne, terapię eradykacyjną $H$. pylori (schemat bez klarytromycyny) $z$ kontynuacją leczenia inhibitorem pompy protonowej, modyfikację leczenia choroby zwyrodnieniowej stawów (odstawienie niesteroidowych leków przeciwzapalnych [NSAID, non-steroid antinflammatory drug]) oraz modyfikację farmakoterapii hipotensyjnej pod kątem nefroprotekcji i unikania nadciśnienia (zmniejszenie dawki ramiprilu do $1 \times 5 \mathrm{mg}$, dołączenie amlodipiny w dawce $1 \times 5 \mathrm{mg})$. W ramach profilaktyki wtórnej nawrotu arytmii zastosowano dotychczasową dawkę beta-adrenolityku oraz zmniejszono dawkę amiodaronu do $100 \mathrm{mg} /$ dobę.
Tabela 2. Wyniki badań dodatkowych w trakcie leczenia szpitalnego pacjentki

\begin{tabular}{lc}
\hline Oznaczenie/badanie & Wartość/opis \\
\hline Stężenie Hgb [g/dl] & 11,0 \\
Odsetek Hct (\%) & 33 \\
Stężenie kreatyniny [mg/dl] & 1,6 \\
Masa ciała [kg] & 85 \\
CCr [ml/min] & 37 \\
aPTT [s] & 34 \\
Stężenie ALT [j./l] & 72 \\
Badanie EKG & Rytm zatokowy 65/min \\
HGB - hemoglobina; HCT (hematocrit) - hematokryt; GFR (glomerular filtration rate) - wskaźnik \\
filtracji kłebuszkowej; CCr (creatinine clearence) - klirens kreatyniny; aPTT (activated partial \\
thromboplastin time) - czas czésciowej tromboplastyny po aktywacji; ALT (alanine aminotransfe- \\
rase) - aminotransferaza alaninowa; EKG - elektrokardiograficzne
\end{tabular}

Zalecono regularną kontrolę parametrów nerkowych, jonogramu, parametrów gospodarki tarczycowej, transaminaz oraz zapisu elektrokardiograficznego (EKG) pod kątem oceny odstępu QT.

Ze względu na świeżo przebyty epizod krwawienia z przewodu pokarmowego oceniono wskazania do ponownego włączenia leczenia przeciwkrzepliwego. $W$ tym celu obliczono punktację w skali $\mathrm{CHA}_{2} \mathrm{DS}_{2} \mathrm{VASc}$ (stratyfikacja ryzyka wystąpienia epizodu zakrzepowo-zatorowego) oraz w skali HAS-BLED (ocena ryzyka ponownego wystąpienia istotnego krwawienia). Biorąc pod uwagę dysfunkcję skurczową lewej komory, wywiad nadciśnienia tętniczego i przebytego zawału serca, płeć żeńską oraz wiek przekraczający 80. rok życia, punktacja w skali $\mathrm{CHA}_{2} \mathrm{DS}_{2}$ VASc wynosiła 6 (wysokie ryzyko), natomiast świeżo przebyty epizod krwotoczny, stężenie kreatyniny przekraczające $1,5 \mathrm{mg} / \mathrm{dl}$, wiek ponad 65 lat oraz stosowanie leków zwiększających ryzyko krwawienia (NSAID) stanowiły składowe punktacji w skali HAS-BLED, która wynosiła 4 (wysokie ryzyko). W tej skali nie uwzględniono natomiast nadciśnienia tętniczego, gdyż pacjentka negowała wartości ciśnienia skurczowego tętniczego ponad $160 \mathrm{~mm} \mathrm{Hg}$ przed przyjęciem. Z powodu wysokiego ryzyka wystąpienia udaru mózgu podjęto decyzję o ponownym włączeniu antykoagulacji. Zgodnie z punktacją w skali SAMeTT ${ }_{2} R_{2}$ (3 pkt.) i uwzględniając choroby towarzyszace, takie jak nadciśnienie tętnicze, przebyty zawał serca z dysfunkcją skurczową lewej komory i upośledzona funkcja nerek, oraz interakcje lekowe (amiodaron będący inhibitorem systemu transportowego glikoproteiny P), zdecydowano o ponownym włączeniu NOAC, tym bardziej że w przypadku zmniejszonych dawek ryzyko krwawienia z przewodu pokarmowego jest względnie niższe w odniesieniu do warfaryny, co potwierdzono w metaanalizie Ruffa i wsp. [1]. Pierwotnie jako optymalne leczenie pacjentce zaproponowano apiksaban w zmniejszonej dawce. Wybór leku uzasadniono korzystnym profilem bezpieczeństwa 
u pacjentów w starszym wieku, z upośledzoną funkcją nerek oraz względnie niższym w stosunku do pozostałych NOAC ryzykiem poważnego krwawienia z przewodu pokarmowego [3]. Ostatecznie jednak leku tego nie włączono z powodu zbyt dużego obciążenia finansowego w okresie hospitalizacji pacjentki (po konsultacji z pacjentką i jej rodziną). Alternatywnie kontynuowano leczenie dabigatranem w zmniejszonej dawce $(2 \times 110 \mathrm{mg})$, biorąc pod uwagę, zgodnie ze zdaniem ekspertów, względnie niższe ryzyko krwawienia z przewodu pokarmowego oraz starszy wiek pacjentki [3].

\section{Omówienie}

Analizując przebieg kliniczny i postępowanie w prezentowanym przypadku, warto zwrócić uwagę na różnorodność czynników wpływających na podwyższone ryzyko wystąpienia powikłań krwotocznych oraz czynników wpływających na wybór rodzaju leczenia przeciwkrzepliwego. Leczenie dabigatranem prowadzone ambulatoryjnie nie było prawidłowo kontrolowane - dawki leku nie dostosowano do zaawansowanego wieku chorej ani do wywiadu upośledzonej funkcji nerek, których funkcja nie była regularnie monitorowana, co mogło doprowadzić do nadmiernej kumulacji leku we krwi. U pacjentki, mimo rozpoznanej choroby refluksowej przełyku, nie wdrożono dotychczas postępowania gastroprotekcyjnego, a było ono tym bardziej wskazane, że pacjentka stosowała przeciwbólowo naproksen z powodu choroby zwyrodnieniowej stawów. Wprawdzie w wyborze NSAID uwzględniono wysokie ryzyko sercowo-naczyniowe pacjentki, jednak - jak dowiedziono w metaanalizie badań randomizowanych obejmujących ponad 350000 chorych, w których porównywano częstość incydentów sercowo-naczyniowych i częstość efektów gastrotoksycznych podczas stosowania NSAID - naproksen (względem koksybów, diklofenaku i ibuprofenu) cechuje najwyższe ryzyko względne (RR, relative risk) wystąpienia działań niepożądanych, w tym krwawień, z górnego odcinka przewodu pokarmowego (RR 4,23; 95\% Cl 2,71-6,56), przy najniższym względnym ryzyku poważnych zdarzeń sercowo-naczyniowych (RR 0,93; 95\% Cl 0,69-1,27) [4]. W przypadku stosowania NOAC rzadko uwzględnia się interakcje lekowe, co może dodatkowo, poza upośledzoną funkcją nerek, prowadzić do kumulacji leku. Wszystkie NOAC są substratami systemu transportera błonowego glikoproteiny $\mathrm{P}$, natomiast wiele leków, w tym amiodaron, to inhibitory tego systemu. Interakcja ta może mieć znaczenie klinicznie u części predysponowanych pacjentów.

Eksperci są zgodni co do zasad wyboru NOAC zależnie od chorób współistniejących. Apiksaban i dabigatran w dawce 2 razy 110 mg są preferowane w przypadku wysokiego ryzyka krwawienia z przewodu pokarmowego, u pacjentów w wieku starszym i z punktacją w skali HAS-BLED
Tabela 3. Akronim GOŹDZIK opisujący zasady postępowania w krwawieniach podczas leczenia doustnymi antykoagulantami niebędącymi antagonistami witaminy K (wg Kluk M.K., Wożakowska-Kapłon B. 2015)

$\begin{array}{cc}\text { Skrót } & \text { Objaśnienie } \\ \text { G } & \text { Grupa krwi } \\ \text { O } & \text { Odstawienie leku } \\ \text { Ź } & \text { Źródło krwawienia } \\ \text { D } & \text { Diureza/dializa } \\ \text { Z } & \text { (Krwio)zastępcze preparaty } \\ \text { I } & \text { Inwersja (antidotum) } \\ \text { K } & \text { Krzepnięcie }\end{array}$

wynoszącą 3 punkty lub więcej. U pacjentów ze wskaźnikiem przesączania kłębuszkowego $15-49 \mathrm{ml} / \mathrm{min}$ preferuje się apiksaban oraz riwaroksaban w dawce $15 \mathrm{mg}$ [3, 5-7].

Wprowadzenie do praktyki klinicznej swoistego antidotum całkowicie i trwale odwracającego efekt przeciwkrzepliwy dabigatranu - idarucizumabu (trwa badanie kliniczne III fazy REVERSE-AD) - oraz planowane wprowadzenie antidotum dla leków z grupy inhibitorów czynnika Xa (trwają badania kliniczne) pozwoli na znaczącą poprawę bezpieczeństwa leczenia przeciwkrzepliwego za pomocą NOAC. $\mathrm{U}$ opisywanej pacjentki nie zastosowano antidotum, mimo dostępności w ramach badania klinicznego, ze względu na stan jednoznacznie ograniczonej świadomości. Obecnie idarucizumab jest już zarejestrowany do stosowania w rutynowej praktyce. W trakcie opieki nad opisaną chorą, uwzględniając niemożność podania swoistego antidotum, opracowano autorski, polskobrzmiący akronim opisujący elementy leczenia krwawień w przebiegu leczenia z użyciem NOAC, nie tylko dabigatranu (GOŹDZIK; tab. 3). Jego kluczowym elementem jest litera „O” oznaczająca konieczność całkowitego odstawienia leku. Należy pilnie oznaczyć grupe krwi („G”) oraz rozważyć przetoczenie preparatów krwi pełnej i krwiozastępczych („Z”). Zawsze istnieje konieczność aktywnego poszukiwania źródła krwawienia („Ź”) w celu wdrożenia leczenia przyczynowego (np. endoskopowego). Jeśli jest możliwe odwrócenie działania leku („l” - inwersja), to należy jak najszybciej zastosować antidotum (obecnie idarucizumab). Litera „D” oznacza konieczność utrzymania odpowiedniej diurezy w celu eliminacji leku przez nerki, a w przypadku dabigatranu - także możliwość przeprowadzenia hemodializy. Litera "K” natomiast oznacza monitorowanie parametrów układu krzepnięcia oraz podawanie osoczowych czynników krzepnięcia (np. rekombinowanego czynnika VII). Akronim ten może ułatwić kompleksowe postępowanie podczas krwawień związanych z NOAC. 


\section{Podsumowanie}

Poważne epizody krwotoczne u pacjentów obciążonych wysokim ryzykiem powikłań zakrzepowo-zatorowych stanowią podstawowy problem kliniczny podczas wyboru leczenia przeciwkrzepliwego. Wysoka punktacja w skali HAS-BLED wskazuje na konieczność ścisłej kontroli czynników ryzyka krwawienia. Korzystny profil farmakobiologiczny u pacjentów po przebytym epizodzie krwawienia z przewodu pokarmowego, z wysoką punktacją w skali
HAS-BLED i istotnie upośledzoną funkcją nerek wykazuje apiksaban.

\section{Konflikt interesów}

Beata Wożakowska-Kapłon - wykłady i udział w komitetach doradczych firm: Boehringer-Ingelheim, Pfizer, Bayer; koordynator krajowy badania REVERSE-AD.

Maciej Krzysztof Kluk, Kamilla Wesołowska, Agnieszka Woronowicz-Chróściel - współbadacze w badaniu REVERSE-AD.

\section{Abstract}

The problem of serious bleeding complications, such as gastrointestinal bleeding, generates the main risk associated with chronic anticoagulation, including non-vitamin $\mathrm{K}$ oral anticoagulants (NOAC), in patients with atrial fibrillation. A presented case report of 81-year old woman demonstrates that recovering from the life-threatening gastrointestinal bleeding is not a contraindication to restart NOAC therapy, especially when the thromboembolic risk is high. NOAC give an opportunity to choose the optimal treatment considering age, renal function as well as $\mathrm{CHA}_{2} \mathrm{DS}_{2} \mathrm{VASc}$ and HAS-BLED scores. Apixaban is suggested to be favoured in patients with high risk of gastrointestinal bleeding recurrence and serious renal function impairment.

Key words: non-vitamin K oral anticoagulants, thromboembolic risk, bleeding risk, gastrointestinal bleeding, dabigatran, apixaban

Folia Cardiologica 2016; 11, 3: 228-232

\section{Piśmiennictwo}

1. Ruff C.T., Giugliano R.P., Braunwald E. i wsp. Comparison of the efficacy and safety of new oral anticoagulants with warfarin in patients with atrial fibrillation: a meta-analysis of randomised trials. Lancet 2014; 383: 955-962.

2. Connolly S.J., Ezekowitz M.D., Yusuf S. i wsp.; Randomized Evaluation of Long-Term Anticoagulation Therapy Investigators. Newly identified events in the RE-LY trial. N. Engl. J. Med. 2010; 363: 1875-1876.

3. Diener H.-C., Aisenberg J., Ansell J. i wsp. Choosing a particular oral anticoagulant and dose for stroke prevention in individual patients with non-valvular atrial fibrillation: part 2. Eur. Heart J. 2016; doi: 10.1093/eurheartj/ehw069.

4. Coxib and traditional NSAID Trialists' (CNT) Collaboration. Vascular and upper gastrointestinal effects of non-steroidal anti-inflammatory drugs: meta-analyses of individual participant data from randomised trials. Lancet 2013; 382: 769-779.

5. Lip G.Y., Lane D.A. Matching the NOAC to the Patient. Remember the Modifiable Bleeding Risk Factors. J. Am. Coll. Cardiol. 2015; 66: 2282-2284.

6. Rosanio S., Keylani A.M., D'Agostino D. i wsp. Pharmacology, benefits, unadressed questions and pragmatic issues of the newer oral anticoagulants for stroke prophylaxis in non-valvular atrial fibrillation and proposal of a management algorithm. Int. J. Cardiol. 2014; 174: 471-482.

7. Savelieva I., Camm A.J. Practical considerations for the using novel oral anticoagulants in patients with atrial fibrillation. Clin. Cardiol. 2014; 37: 32-47. 